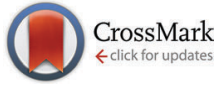

Cite this: Chem. Commun., 2014, 50, 10055

Received 16th May 2014, Accepted 11th July 2014

DOI: $10.1039 / c 4 c c 03764 b$

www.rsc.org/chemcomm

\section{A zirconium squarate metal-organic framework with modulator-dependent molecular sieving properties $\dagger$}

\author{
Bart Bueken, ${ }^{a}$ Helge Reinsch, ${ }^{a}$ Nele Reimer, ${ }^{b}$ Ivo Stassen, ${ }^{a}$ Frederik Vermoortele, ${ }^{a}$ \\ Rob Ameloot, ${ }^{a}$ Norbert Stock, ${ }^{b}$ Christine E. A. Kirschhock ${ }^{a}$ and Dirk De Vos ${ }^{\star a}$
}

\begin{abstract}
We report the first zirconium metal-organic framework based on squaric acid, representing the member with the smallest unit cell in the isoreticular UiO-66 family. Its molecular sieving properties are strongly influenced by the monocarboxylic acid modulator incorporated during synthesis.
\end{abstract}

Metal-organic frameworks (MOFs) are hybrid materials consisting of metal ions or clusters bridged by polytopic organic linkers. ${ }^{1}$ MOFs often have large specific surface areas and porosities, which can easily be fine-tuned due to their chemical flexibility. ${ }^{2,3}$ In this regard the principle of isoreticularity is frequently applied to construct isotopological frameworks with varying pore sizes by using linkers with the same connectivity but different lengths. Wellknown examples are the IRMOF-series based on expanded or functionalized versions of MOF-5 and MOF- $74,4,5$ and the cubic MOFs based on the Zr-terephthalate UiO-66. ${ }^{6}$ Recently several publications have highlighted the possibility to engineer the porosity of the latter group of MOFs via the incorporation of monocarboxylate modulators or linker fragments such as acetate or benzoate into the framework..$^{7-9}$ During synthesis these modulators aid the formation of the characteristic hexanuclear $\mathrm{Zr}$ cluster but also directly compete with the dicarboxylate linkers for binding to it, ultimately leading to a framework in which the linkers are partially replaced by the modulator. Additionally, some modulators can be post-synthetically removed from the lattice. ${ }^{9}$ Both the incorporation and the subsequent removal of modulators can be considered as strategies to generate defects within the framework, resulting in a material with larger pores.

\footnotetext{
${ }^{a}$ Centre for Surface Chemistry and Catalysis, KU Leuven - University of Leuven, Kasteelpark Arenberg 23 post box 2461, 3001 Leuven, Belgium. E-mail:dirk.devos@biw.kuleuven.be

${ }^{b}$ Institut für Anorganische Chemie, Christian-Albrechts-Unversität, Max-Eyth Straße 2, D 24118 Kiel, Germany

$\dagger$ Electronic supplementary information (ESI) available: Experimental details, structure solution and refinement data and crystal structure summary of ZrSQU and HFSQU, FTIR spectra, TGA data, EDX data, gas uptake comparison with UiO66 and Zr-fumarate. CCDC 1003940 and 1003941. For ESI and crystallographic data in CIF or other electronic format see DOI: $10.1039 / \mathrm{c} 4 \mathrm{cc} 03764 \mathrm{~b}$
}

a)<smiles></smiles>

d)

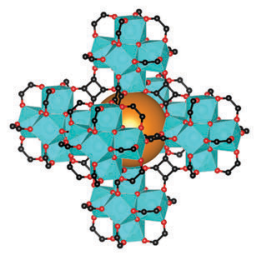

c)
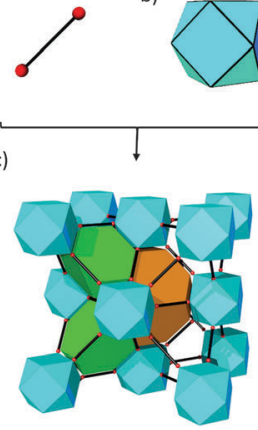

b)

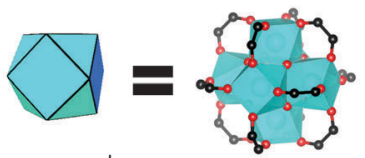

e)

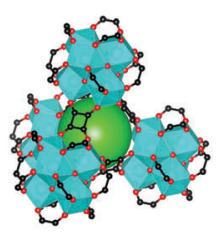

Fig. 1 Structural and topological representation of ZrSQU. SQU linkers (a) and $\mathrm{Zr}_{6} \mathrm{O}_{4}(\mathrm{OH})_{4}\left(\mathrm{C}_{2} \mathrm{O}_{2}\right)_{12}$ clusters (b) stack in an fcu-lattice (c), delineating octahedral (orange, d) and tetrahedral (green, e) cages with triangular windows. ( $\mathrm{Zr}=$ blue; $\mathrm{O}=$ red; $\mathrm{C}=$ black).

Here we demonstrate how modulation-based porosity engineering can be extended down the line of the isoreticular UiO-66 series to the point where the intrinsic pore size of the defect-free lattice would be too small to allow for the uptake of guest molecules, rendering such frameworks essentially non-porous. Controlling modulator-induced linker defects provides the key to influencing the porosity of such MOFs. To explore this concept, we applied squaric acid $\left(\mathrm{C}_{4} \mathrm{O}_{4} \mathrm{H}_{2}\right.$, SQA, Fig. 1a) as a linker for Zr-MOFs. SQA is a non-carboxylic, organic acid which is known to take on a variety of coordination modes with metal ions upon deprotonation to squarate $\left(\mathrm{C}_{4} \mathrm{O}_{4}{ }^{2-}\right.$, SQU). ${ }^{10,11}$ Due to the short distance between coordinating O-atoms $(\sim 3.2 \AA$ ss. $\sim 7.0 \AA$ for terephthalate) only a small number of porous coordination polymers based on SQA have been reported, ${ }^{12-16}$ and no zirconium-based squarate has been described to date. The first Zr-based squarate MOF (ZrSQU), the MOF with the smallest unit cell isoreticular to UiO-66, is reported here. While no accessible porosity is expected based on the crystal structure, we show that the incorporation of small modulators effectively confers molecular sieving properties to this framework. The choice of modulator allows for a subtle control on the size of gas molecules that can be adsorbed. 
ZrSQU crystallizes as a microcrystalline powder of intergrown aggregates (Fig. 2) upon reaction of squaric acid with $\mathrm{ZrCl}_{4}$ in a mixture of dimethylformamide (DMF), aqueous $\mathrm{HCl}$ and a monocarboxylic modulator, either acetic acid or formic acid, at $110{ }^{\circ} \mathrm{C}$ for $2 \mathrm{~h}(92 \%$ yield based on $\mathrm{Zr})$. Similar to several other Zr-MOFs, the presence of a modulator is required to form a crystalline material. ${ }^{17-24}$ By increasing the amounts of $\mathrm{HCl}$ and modulator during synthesis, the crystallinity of the formed product can greatly be increased (Fig. S1†). Materials of comparable crystallinity are obtained by using either acetic or formic acid (Fig. S2 $\dagger$ ). These compounds are hereafter named $\mathrm{ZrSQU}_{\mathrm{A}}$ and $\mathrm{ZrSQU}_{\mathrm{F}}$ respectively. No effect on particle size is observed when varying the modulator or its concentration, most likely due to the fast nucleation. The isostructural Hf-analogue can easily be obtained by replacing $\mathrm{ZrCl}_{4}$ with equimolar amounts of $\mathrm{HfCl}_{4}$ (Fig. S3 $\dagger$ ).

The structure of ZrSQU was solved from powder XRD data in the cubic space group $F m \overline{3} m(a=15.784(3) \AA)$ and it is isoreticular to that of UiO-66. ${ }^{6}$ The inorganic building unit consists of six $\mathrm{Zr}^{4+}$-ions each occupying the vertex of an octahedron that is face-capped by $\mu_{3}-\mathrm{O}$ or $\mu_{3}-\mathrm{OH}$ groups, while its edges are bridged by twelve $\mathrm{C}_{2} \mathrm{O}_{2}{ }^{-}$ groups corresponding to half a squarate anion (Fig. 1b). Due to the twelve-fold connectivity the clusters arrange in a face-centered cubic stacking, resulting in a lattice with the fcu-topology (Fig. 1c). The two broad reflections around $5.5^{\circ} 2 \theta$, which are forbidden for the $F m \overline{3} m$ space group, have been observed for other Zr-MOFs. While their origin is not yet fully elucidated, these reflections are allowed for a primitive cubic phase with the same cell parameter as that of the face-centered phase. This in turn could hint at the presence of primitive defect regions within the ZrSQU lattice. ${ }^{25,26}$

The ZrSQU framework features both octahedral and tetrahedral cages with diameters of $5.6 \AA$ and $4.7 \AA$ respectively (Fig. 1), enclosed by triangular windows. The diameter of the largest sphere that can pass through these windows is approximately $2.4 \AA$, taking into account the Van der Waals radii of the atoms lining the pores (Fig. S4 $\dagger$ ). Based on the crystal structure model a void volume of $32.6 \%$ (PLATON, ${ }^{27}$ probe $1.2 \AA$ ) was calculated. Residual electron density was found by Fourier analysis in both types of voids and is most likely due to guest

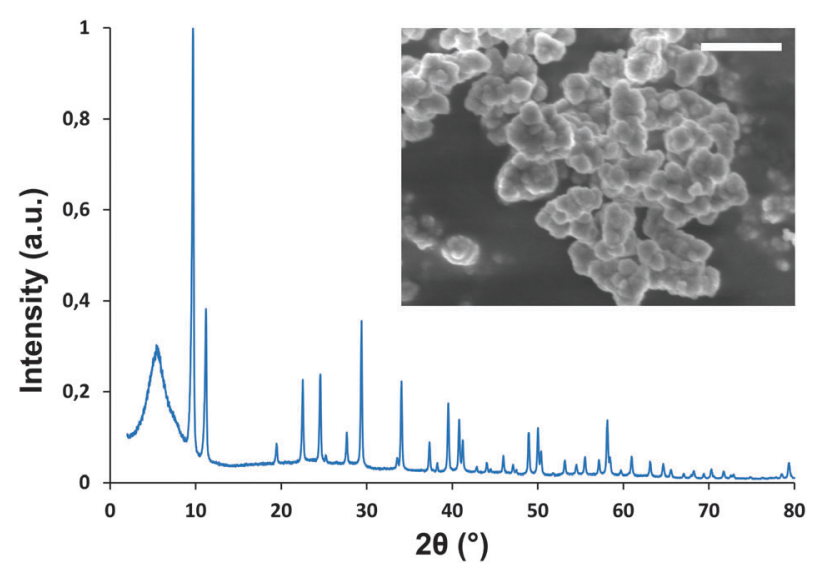

Fig. 2 Experimental powder pattern for ZrSQU. Inset: SEM image of aggregated ZrSQU crystallites (scale bar: $2 \mu \mathrm{m}$ ).

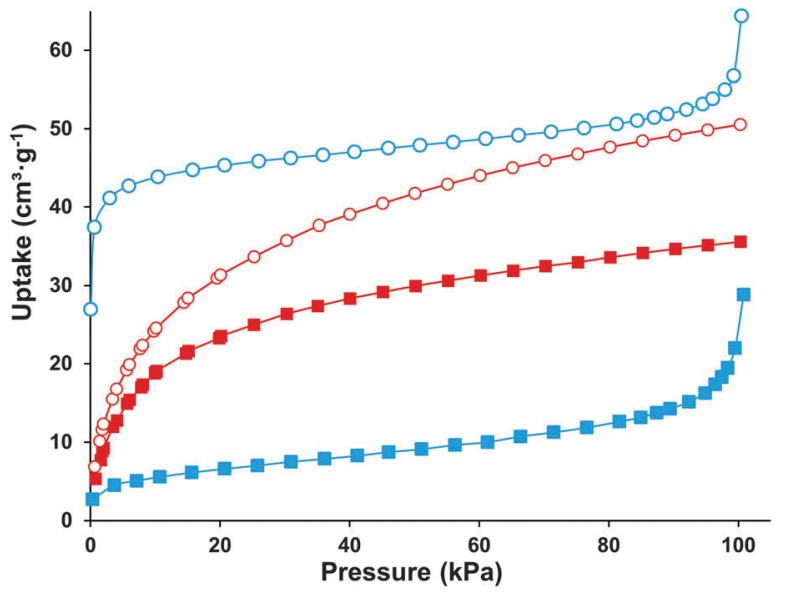

Fig. 3 Adsorption isotherms for $\mathrm{N}_{2}$ (blue) and $\mathrm{H}_{2}$ (red) measured at $77 \mathrm{~K}$ on $\mathrm{ZrSQU}_{\mathrm{A}}$ (square) and $\mathrm{ZrSQU}_{\mathrm{F}}$ (circle) outgassed at $10^{-4}$ bar at $373 \mathrm{~K}$ for $4 \mathrm{~h}$.

molecules (water, DMF, modulator) occluded in the cages during synthesis. Following thermal activation under vacuum, $\mathrm{N}_{2}$ physisorption (Fig. 3) revealed a type II isotherm for $\mathrm{ZrSQU}_{\mathrm{A}}$, which is indicative of a non-porous or macroporous material. $\mathrm{ZrSQU}_{\mathrm{F}}$ on the other hand showed a clear type $\mathrm{I}$ isotherm reaching a micropore uptake of $40.4 \mathrm{~cm}^{3} \mathrm{~g}^{-1} \mathrm{~N}_{2}$. A multipoint BET surface area ${ }^{28}$ of $179 \mathrm{~m}^{2} \mathrm{~g}^{-1}$ was determined for the latter, taking into account the consistency criteria developed for MOFs. ${ }^{29}$ Note that theoretically, based on Zeo++ calculations for the ideal crystal lattice (3.861 A probe diameter), ZrSQU does not have any capacity for $\mathrm{N}_{2} \cdot{ }^{30} \mathrm{H}_{2}$ adsorption demonstrated that both $\mathrm{ZrSQU}_{\mathrm{A}}$ and $\mathrm{ZrSQU}_{\mathrm{F}}$ can adsorb this smaller probe molecule (kinetic diameter $2.82 \AA$ ), with a capacity of $35.6 \mathrm{~cm}^{3} \mathrm{~g}^{-1}$ and $50.5 \mathrm{~cm}^{3} \mathrm{~g}^{-1}$ respectively at 1 bar and $77 \mathrm{~K}$ (Fig. 3). The type I isotherms clearly show that hydrogen is adsorbed in the micropores of both materials.

The fact that ZrSQU is able to adsorb gasses that have kinetic diameters larger than the $2.4 \AA$ window size of the perfect lattice can be explained by the presence of framework defects. To prove that the origin of these defects lies in the incorporation of modulator during synthesis, FTIR measurements were performed on both materials in $\mathrm{KBr}$ (Fig. S5 and S6 $\dagger$ ). Indeed, apart from the broad band centered around $1510 \mathrm{~cm}^{-1}$, which is assigned to the combined $\nu_{\mathrm{C}=\mathrm{C}}$ and $\nu_{\mathrm{C}=\mathrm{O}}$ modes of SQU, clear proof for the incorporation of formate or acetate ions comes from the $\nu_{\mathrm{C}=\mathrm{O}}$ vibration at $1655 \mathrm{~cm}^{-1}$ as well as the $\nu_{\mathrm{C}-\mathrm{H}}$ modes at $2965 \mathrm{~cm}^{-1}$ and $2861 \mathrm{~cm}^{-1}$. In order to quantify the amount of modulator and thus the composition of ZrSQU, a combined thermogravimetric (TG) and ${ }^{1} \mathrm{H}-\mathrm{NMR}$ approach was used. The TG profiles of $\mathrm{ZrSQU}_{\mathrm{A}}$ and $\mathrm{ZrSQU}_{\mathrm{F}}$ (Fig. 4) show three distinct steps. A first step from the onset of the measurement up to $210{ }^{\circ} \mathrm{C}$ is attributed to the removal of occluded water, solvent and physisorbed modulator. A second step between $210{ }^{\circ} \mathrm{C}$ and $350{ }^{\circ} \mathrm{C}$ coincides with decomposition of the linker. ${ }^{31}$ The resulting phase was determined to be an amorphous Zr-carbonate by FTIR spectroscopy, which transforms to tetragonal $\mathrm{ZrO}_{2}$ at $630{ }^{\circ} \mathrm{C}$ (Fig. S7 and $\mathrm{S} 8 \dagger$ ). While the actual framework decomposition starts at $210{ }^{\circ} \mathrm{C}$, the material loses 


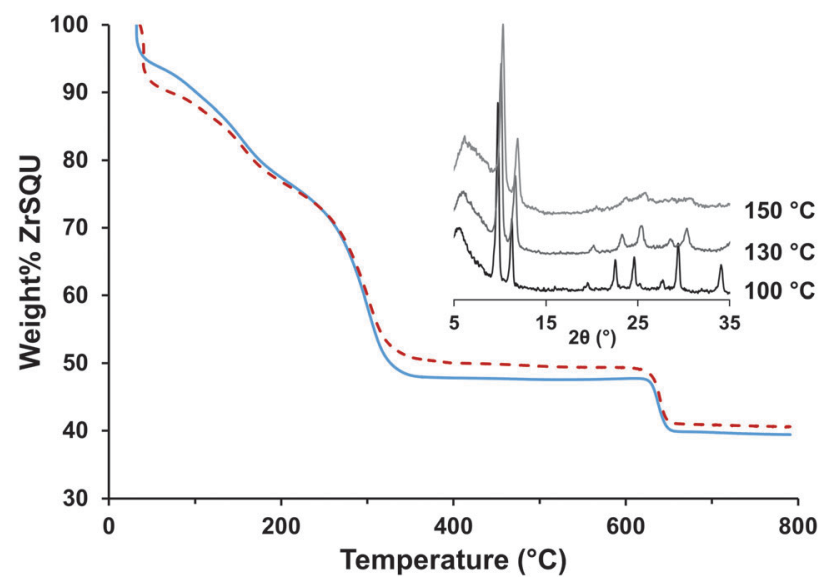

Fig. 4 TG profiles for as synthesized $\mathrm{ZrSQU}_{\mathrm{A}}$ (blue solid) and $\mathrm{ZrSQU}_{\mathrm{F}}$ (red dash) measured under O2. The framework loses long range order in the $130-150{ }^{\circ} \mathrm{C}$ range with a decrease in cell volume (inset).

some of its crystallinity in the $130-150{ }^{\circ} \mathrm{C}$ range. We believe that in this range the pressure exerted by occluded water molecules irreversibly damages the lattice, for instance by partial hydrolysis of the SQU-Zr bond. Because of the strong delocalization of electrons in SQU, the bond between the soft electron-poor SQU anion and the hard $\mathrm{Zr}^{4+}$ is weaker than the $\mathrm{Zr}$-carboxylate bonds in other Zr-MOFs, ${ }^{32}$ making such hydrolysis plausible. This partial collapse is irreversible and is accompanied by a decrease of the cell parameter to approximately $14.88 \AA$ A. Nevertheless, the 111 and 200 reflections remain clearly visible indicating the persistence of long range order. Pretreating the materials for sorption had a similar effect, with $\mathrm{ZrSQU}_{\mathrm{F}}$ being less prone to collapse than $\mathrm{ZrSQU}_{\mathrm{A}}$ (Fig. S9†). At room temperature however, ZrSQU is stable in water for at least 3 days (Fig. S10 $\dagger$ ).

In contrast with earlier observations on some other modulated Zr-MOFs, ${ }^{9}$ a separate step of modulator removal from the ZrSQU framework is not observed in the TG profile. Rather a combined decomposition and modulator volatilization step is observed because of the stronger modulator-cluster bonding. To accurately determine the composition of ZrSQU the activated solids were therefore dissolved in $\mathrm{d}_{6}$-DMSO using $\mathrm{CsF}^{33}$ and ${ }^{1} \mathrm{H}$-NMR spectra were recorded. We found $\mathrm{ZrSQU}_{\mathrm{A}}$ and $\mathrm{ZrSQU}_{\mathrm{F}}$ to contain $6.4 \mathrm{wt} \%$ acetate and $10.5 \mathrm{wt} \%$ formate, respectively. Combining these results with the TG data gives the structural formulae $\mathrm{Zr}_{6} \mathrm{O}_{4}(\mathrm{OH})_{4}(\mathrm{SQU})_{5.25}\left(\mathrm{CH}_{3} \mathrm{COO}\right)_{1.5}$ and $\mathrm{Zr}_{6} \mathrm{O}_{4}(\mathrm{OH})_{4}(\mathrm{SQU})_{4.45}(\mathrm{HCOO})_{3.1}$. These are approximate formulae which should be regarded as representative models for the actual materials. In EDX measurements, no $\mathrm{Cl}^{-}$was detected at all (Fig. S11†); hence it is justified to balance all positive charges of the $\mathrm{Zr}$ cations by $\mathrm{O}^{2-}, \mathrm{OH}^{-}$, SQU and modulator. The amount of incorporated modulator can be altered by changing the initial amount present in the synthesis mixture. For instance, a molar ratio of $360 / 1$ acetic acid/ $\mathrm{ZrCl}_{4}$ leads to an incorporation of $9.5 \mathrm{wt} \%$ acetic acid in the activated solid, while a 330/1 formic acid/ $\mathrm{ZrCl}_{4}$-ratio leaves $17.1 \mathrm{wt} \%$ formate built into the MOF. Clearly, a significant amount of modulator is incorporated during the synthesis of ZrSQU. Formate is able to compete better with SQU than acetate for binding to the cluster due to the fact that formic acid is a slightly stronger acid than acetic acid. Given the highly acidic synthesis conditions, it is therefore built in in larger amounts. Additionally, as formate is smaller than acetate (Van der Waals volume $\sim 40 \AA^{3} v s$. $\sim 57 \AA^{3}$ ) it is expected that formate suffers less from sterical hindrance within the framework, allowing more molecules to be incorporated.

As the stoichiometric substitution of one SQU $\left(\sim 79 \AA^{3}\right)$ for two formate ions does not strongly affect the free volume within the unit cell, we believe that the increased porosity in $\mathrm{ZrSQU}_{\mathrm{F}}$ is rather due to a change in size and shape of the triangular windows. The cluster-bound formates could also act as a trapdoor by tilting out of plane around their $\mathrm{O}-\mathrm{O}$ axis, further increasing the window size. The bulkier acetate ions are more sterically constrained, which could explain why $\mathrm{ZrSQU}_{\mathrm{A}}$ cannot take up $\mathrm{N}_{2}$, but is porous for the smaller $\mathrm{H}_{2}$. This additional sterical bulk further rationalizes the lower $\mathrm{H}_{2}$-uptake of $\mathrm{ZrSQU}_{\mathrm{A}}$ compared to $\mathrm{ZrSQU}_{\mathrm{F}}$. The size-selective uptake of gas molecules in $\mathrm{ZrSQU}_{\mathrm{A}}$, which is absent in its formate-containing counterpart, is a clear demonstration of how selecting the appropriate modulator can have a distinct influence on the molecular sieving properties of the formed MOFs through a subtle alteration of the parent structure. $\mathrm{ZrSQU}_{\mathrm{A}}$ could thus be exploited in the purification of small gasses, e.g. $\mathrm{H}_{2}$ or He. A comparison with other Zr-MOFs is provided in the ESI. $\dagger$

To conclude, we reported the synthesis and characterization of the first $\mathrm{Zr}$ squarate MOF, which is the smallest member of the isoreticular series based on UiO-66. Accessible microporosity is created in this theoretically non-porous material by the incorporation of different modulators during synthesis, the choice of which allows fine-tuning of ZrSQU's gas sorption properties.

BB, IS and DDV acknowledge the FWO Flanders for financial support. NR and NS are thankful for the support of the DFG (SPP1362). The authors would like to thank K. Duerinckx for NMR measurements and P. Valvekens for $\mathrm{N}_{2}$ sorption.

\section{Notes and references}

1 B. Van de Voorde, B. Bueken, J. Denayer and D. De Vos, Chem. Soc. Rev., 2014, DOI: 10.1039/C4CS00006D.

2 C. Janiak and J. K. Vieth, New J. Chem., 2010, 34, 2366.

3 H. Furukawa, K. E. Cordova, M. O'Keeffe and O. M. Yaghi, Science, 2013, 341(80), 1230444.

4 M. Eddaoudi, J. Kim, N. Rosi, D. Vodak, J. Wachter, M. O'Keeffe and O. M. Yaghi, Science, 2002, 295, 469-472.

5 H. Deng, S. Grunder, K. E. Cordova, C. Valente, H. Furukawa, M. Hmadeh, F. Gándara, A. C. Whalley, Z. Liu, S. Asahina, H. Kazumori, M. O'Keeffe, O. Terasaki, J. F. Stoddart and O. M. Yaghi, Science, 2012, 336, 1018-1023.

6 J. H. Cavka, S. Jakobsen, U. Olsbye, N. Guillou, C. Lamberti, S. Bordiga and K. P. Lillerud, J. Am. Chem. Soc., 2008, 130, 13850-13851.

7 J. Park, Z. U. Wang, L.-B. Sun, Y.-P. Chen and H.-C. Zhou, J. Am. Chem. Soc., 2012, 134, 20110-20116.

8 H. Wu, Y. S. Chua, V. Krungleviciute, M. Tyagi, P. Chen, T. Yildirim and W. Zhou, J. Am. Chem. Soc., 2013, 135, 10525-10532.

9 F. Vermoortele, B. Bueken, G. Le Bars, B. Van de Voorde, M. Vandichel, K. Houthoofd, A. Vimont, M. Daturi, M. Waroquier, V. Van Speybroeck, C. Kirschhock and D. E. De Vos, J. Am. Chem. Soc., 2013, 135, 11465-11468.

10 R. West and H. Y. Niu, J. Am. Chem. Soc., 1963, 85, 2589-2590. 
11 J.-C. Trombe, J.-F. Petit and A. Gleizes, Inorg. Chim. Acta, 1990, 167, 69-81.

12 C. Robl and A. Weiss, Mater. Res. Bull., 1987, 22, 373-380.

13 S. O. H. Gutschke, M. Molinier, A. K. Powell and P. T. Wood, Angew. Chem., Int. Ed. Engl., 1997, 36, 991-992.

14 S. Neeraj, M. L. Noy, C. N. R. Rao and A. K. Cheetham, Solid State Sci., 2002, 4, 1231-1236.

15 R. E. Dinnebier, H. Nuss and M. Jansen, Z. Anorg. Allg. Chem., 2005, 631, 2328-2332.

16 S. Sharma and M. Jansen, Z. Anorg. Allg. Chem., 2008, 634, 1911-1914.

17 A. Schaate, P. Roy, A. Godt, J. Lippke, F. Waltz, M. Wiebcke and P. Behrens, Chemistry, 2011, 17, 6643-6651.

18 A. Schaate, P. Roy, T. Preusse, S. J. Lohmeier, A. Godt and P. Behrens, Chemistry, 2011, 17, 9320-9325.

19 G. Wißmann, A. Schaate, S. Lilienthal, I. Bremer, A. M. Schneider and P. Behrens, Microporous Mesoporous Mater., 2012, 152, 64-70.

20 A. Schaate, S. Dühnen, G. Platz, S. Lilienthal, A. M. Schneider and P. Behrens, Eur. J. Inorg. Chem., 2012, 790-796.

21 V. Bon, V. Senkovskyy, I. Senkovska and S. Kaskel, Chem. Commun., 2012, 48, 8407-8409.

22 V. Bon, I. Senkovska, M. S. Weiss and S. Kaskel, CrystEngComm, 2013, 15, 9572-9577.
23 V. Bon, I. Senkovska, I. A. Baburin and S. Kaskel, Cryst. Growth Des., 2013, 13, 1231-1237.

24 H. Furukawa, F. Gándara, Y.-B. Zhang, J. Jiang, W. L. Queen, M. R. Hudson and O. M. Yaghi, J. Am. Chem. Soc., 2014, 136, 4369-4381.

25 M. Kandiah, M. H. Nilsen, S. Usseglio, S. Jakobsen, U. Olsbye, M. Tilset, C. Larabi, E. A. Quadrelli, F. Bonino and K. P. Lillerud, Chem. Mater., 2010, 22, 6632-6640.

26 S. Jakobsen, D. Gianolio, D. Wragg, M. H. Nilsen, H. Emerich, S. Bordiga, C. Lamberti, U. Olsbye, M. Tilset and K. Lillerud, Phys. Rev. B: Condens. Matter Mater. Phys., 2012, 86, 125429.

27 A. L. Spek, Acta Crystallogr., Sect. D, 2009, 65, 148-155.

28 J. Rouquerol, P. L. Llewellyn and F. Rouquerol, Stud. Surf. Sci. Catal., 2007, 166, 49-56.

29 T. Duren, F. Millange, G. Ferey, K. S. Walton and R. Q. Snurr, J. Phys. Chem. C, 2007, 111, 15350-15356.

30 T. F. Willems, C. H. Rycroft, M. Kazi, J. C. Meza and M. Haranczyk, Microporous Mesoporous Mater., 2012, 149, 134-141.

31 K.-S. Lee, J. Jung Kweon, I.-H. Oh and C. Eui Lee, J. Phys. Chem. Solids, 2012, 73, 890-895.

32 R. G. Pearson, J. Chem. Educ., 1968, 45, 581.

33 P. Roy, A. Schaate, P. Behrens and A. Godt, Chemistry, 2012, 18, 6979-6985. 